\title{
Lifestyle risk factors in an urban South African community
}

\author{
SCD Wright, M Cur Nursing, D Tech Nursing \\ Senior lecturer, Adelaide Tambo School of Nursing Science, Tshwane University of Technology, Tshwane, South \\ Africa \\ TS Ramukumba, MSc Nursing \\ Lecturer, Adelaide Tambo School of Nursing Science, Tshwane University of Technology, Tshwane, South Africa
}

Key words: Lifestyle risks, obesity, physical inactivity, hypertension, waisthip ratio, health promotion

\section{Correspondence address: \\ Dr SCD Wright}

Adelaide Tambo School of Nursing Science

Tshwane University of Technology

Private bag $\times 680$

Pretoria

Gauteng

0001

Tel: (012) 382-5470

Fax: (012) 382-5033

Email: wrightscd@tut.ac.za

\section{Abstract: Curationis 31(1): 68-76}

The research question addressed in the study was to determine the prevalence of the following lifestyle risk factors: obesity, waist-hip ratio, physical inactivity, high blood glucose, and hypertension in an urban community. The research objective for the study was to determine the prevalence of specific risk factors in an urban community. Based on the results, a health intervention could be planned and implemented to reduce the prevalence of the risk factors and the possibility of chronic noncommunicable diseases in later life. The design was a quantitative survey using physical measurement and a structured questionnaire. The target population of the study was black urban adults $(\mathrm{n}=218)$. The sampling method was convenient and purposive. The results of the study indicated that the prevalence of hypertension and obesity were higher than the national prevalence for South Africa. The waist-hip ratio revealed that $20 \%$ of the men and $49.7 \%$ of the women were at risk for cardiovascular disease. High blood glucose levels were demonstrated for $21.6 \%$ of the group. Physical activity was also shown to be inadequate. In conclusion, the potential for cardiovascular and metabolic health problems in future is high. It is recommended that an intervention, based on the results of the study, should and must be developed and implemented. The more challenging question is to know what to do and how to do it. A framework is suggested to guide the development of an intervention.

\section{Introduction}

Training student nurses in Community Health Nursing includes service learning opportunities to provide the experiential learning prescribed by the curriculum. To comply with the requirements, the Department of Nursing Science of Tshwane University of Technology participates in various community-based projects in urban settings. From participant observation, obesity and inactivity was prevalent amongst the members of the community, especially so among the women. As the department has a long-term relationship with the community, a decision was taken to approach the community to measure specific lifestyle risks with the aim of developing health promoting interventions to reduce the prevalence of these risk factors.

Lifestyle risks result in noncommunicable diseases, typically metabolic or cardiovascular in nature and usually chronic. These diseases were the main cause of death of South Africans in 2000 (Reddy, 2004:175-179). Reddy reports that in 2000 in South Africa, noncommunicable diseases accounted for $40 \%$ of all deaths in women and $36 \%$ of deaths among men. The most prominent chronic conditions in South Africa include cardiovascular disease, diabetes, cancer, and chronic obstructive pulmonary disease. In addition, chronic diseases are largely preventable if effective interventions can be targeted 


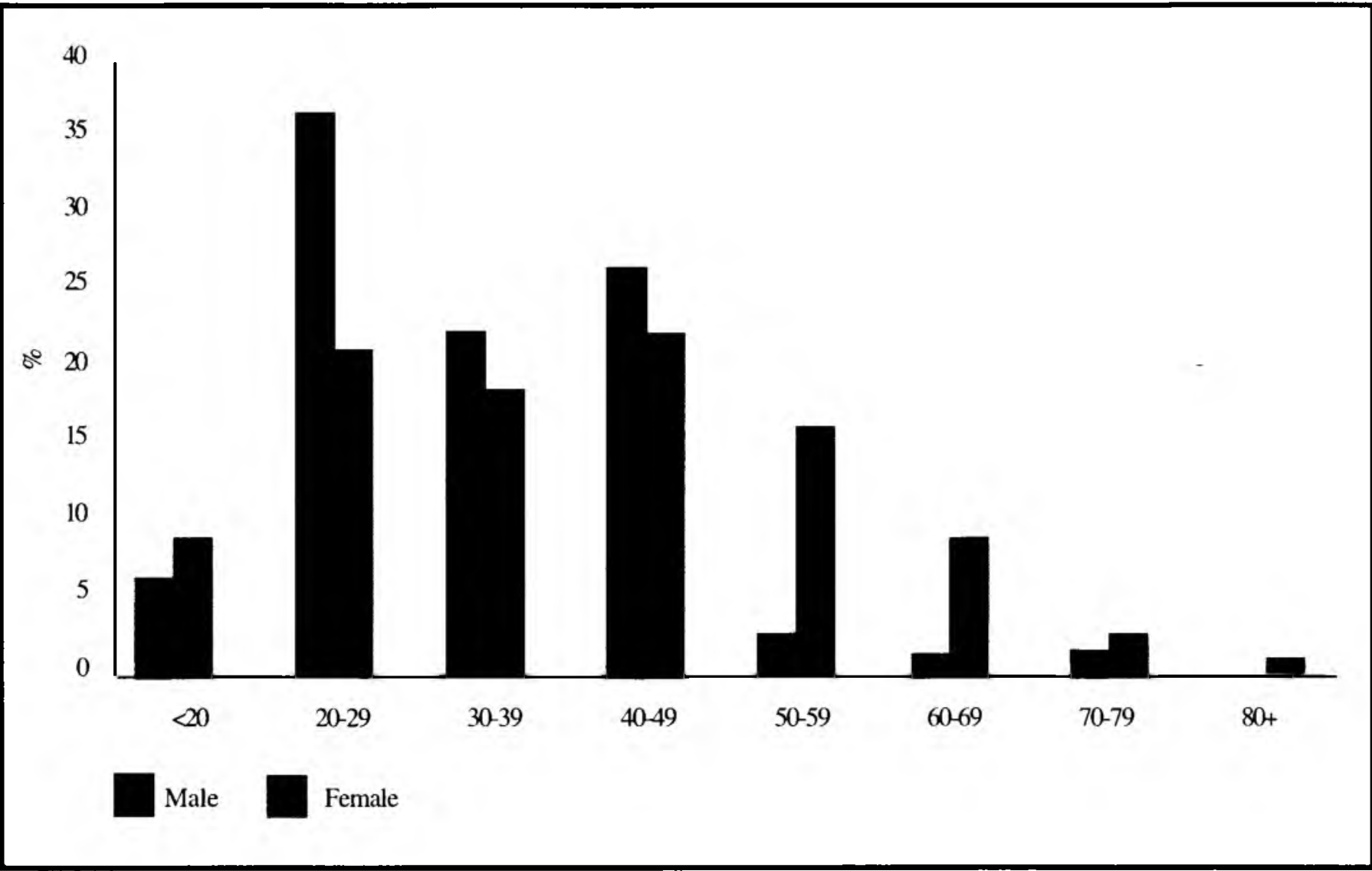

at the risk factors and the determinants of the risk factors.

One determinant of health risks is urbanisation. Urbanisation causes changes in lifestyle which often result in health risks that were previously unfamiliar in the specific population group. A result of the unfamiliarity is a lack of knowledge regarding the causative factors and prevention methods, which may lead to the disease progressing to an advanced stage before a diagnosis can be made (Kruger, Venter \& Vorster, 2003:16). In addition, due to the unfamiliarity, people often fear the disease and deny its existence. As a result, the mortality rate is high.

Steyn et al. (1997:1350) reported several factors that aggravate the health risks associated with urbanisation. The first is that people who spent larger proportions of their lives in an urban setting tended to have unhealthier lifestyles and are at greater risk for chronic non-communicable disease compared with their less urbanized counterparts. In addition, men and women were also found to have different patterns of urbanisation. Traditionally, men were urbanised for longer periods than women due to participation in the economic sector.

Another key risk factor due to urbanisation is changes in a person's diet and the resultant obesity. Ill-considered changes in dietary intake are occurring more frequently among blacks (Bourne, Lambert \& Steyn, 2002:157). Fat intake has increased from $16.4 \%$ to $26.2 \%$ of total energy (a relative increase of $59.7 \%$ ), while carbohydrate intake has decreased from $69.3 \%$ to $61.7 \%$ of total energy (a relative decrease of $10.9 \%$ ) in the past 50 years. The varied risks related to such a change in diet are compounded by persons' perceptions of what is considered as normal weight. Reddy reports that according to World Health Organization standards, $29 \%$ of men and $56 \%$ of women in South Africa are overweight (Reddy, 2004:182). A comparison between people's actual weight categories as measured by body mass index (BMI) and their perceived weight indicates a disparity: $9 \%$ of males perceive themselves to be overweight whereas $29 \%$ are overweight and $21 \%$ of the women perceive themselves to be overweight when in fact $56 \%$ are overweight.

Obesity is a significant risk factor for a range of non-communicable diseases, including

cardiovascular, gastrointestinal, gall-bladder and liver disease, sleep apnoea and diabetes mellitus. According to the International Council of Nurses (2003), obesity is the second leading cause of preventable death after smoking. Urban men and women are also more likely to be overweight. Physical inactivity, a consequence of a more Western lifestyle, is closely associated with obesity and non-communicable disease in later life.

Black adults in an urban environment appear to be especially vulnerable to excessive increases in blood pressure, which leads to hypertension in later life (van Rooyen et al., 2002:69). In support, Peltzer (2001:52) reported that of the estimated 5.5 million people in South Africa with an elevated blood pressure, 3 million are black males. The national prevalence of hypertension in blacks is $24.4 \%$, using the cut-off point of $140 / 90$ $\mathrm{mmHg}$. As is well known, hypertension is a risk factor for cardiovascular disease, specifically ischemic heart disease and peripheral vascular disease. Behavioural patterns in terms of food consumption and salt use have a direct influence on hypertension.

The purpose of the article is to report on 


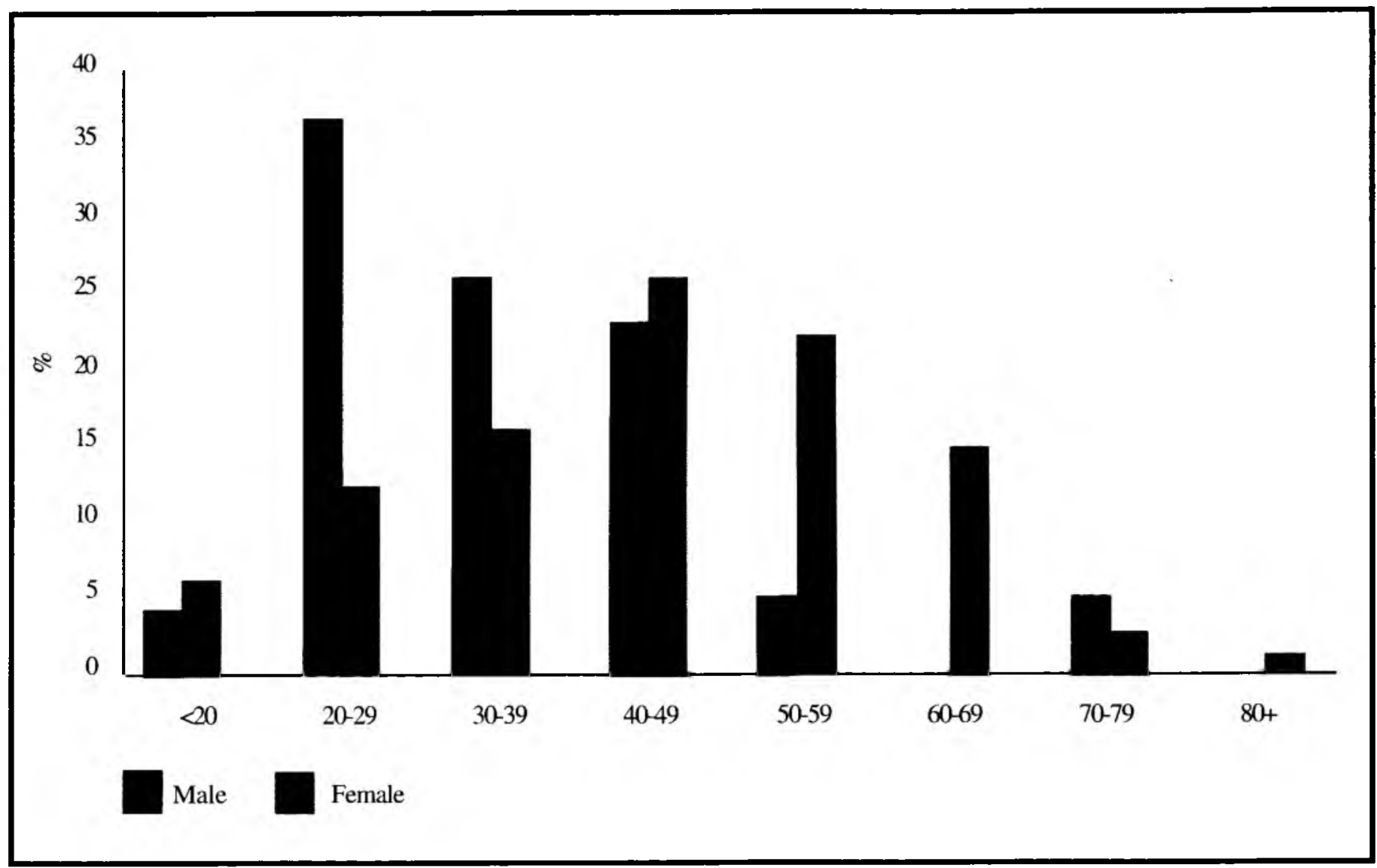

the results of the lifestyle risk survey in the urban community and to discuss the question: what now? Changes in lifestyle are unfortunately not easy to accomplish, especially so if the person who has an identified risk factor is still feeling healthy.

\section{Research question}

The research question addressed in the study was to determine the prevalence of the following lifestyle risk factors: obesity, waist-hip ratio, physical inactivity, high blood glucose, and hypertension in an urban community.

\section{Objectives}

The objective for the study was to determine the prevalence of specific lifestyle risk factors: obesity, waist-hip ratio, physical inactivity, high blood glucose, and hypertension in an urban community. Based on the results of the survey, a health intervention could be planned and implemented to reduce the long-term consequences and chronic non-communicable diseases in later life.

\section{Research methods \\ Design}

The strategy for the study was exploratory (Burns \& Grove, 1997:30).
The design was a quantitative survey.

\section{Population}

The target population of the study were adults living in an urban community. All the adults (above 18 years) in one church community were invited to participate in the study. The community was informed of the study by the pastor of the church the Sunday before the actual data gathering took place.

\section{Sampling method and sample size}

The sampling method was convenient and as such the results are not generalisable to the greater South African population. The sample size was 218 participants $(n=218)$. The majority of the group $(77.5 \%)$ were women. Figure 1 illustrates the difference in the distribution of the males and females in the age groups. The men who participated in the study tended to be younger; almost $92 \%$ of the males were younger than 49 years whilst the women were more evenly spread throughout the age groups.

\section{Data gathering}

Two data gathering methods, physical measurement and self report were used.
Several physical measurements, blood pressure, weight and height, hip and waist circumference, blood glucose level and physical activity, were measured to identify risk factors for cardiovascular disease. Prepared forms were available to record the measurements directly. A short questionnaire was used to gather the data relating to physical activity. The field workers conducted a structured interview with the participants to obtain the data to prevent participants with low literacy from being excluded from the study.

The students and nursing personnel of the Department of Nursing Science participated in the study as field workers. The participants were informed about the procedures and obtained informed consent before data gathering commenced. Where necessary, the informed consent information was translated to ensure full understanding.

To ensure reliable data, the following measures were implemented:

- $\quad$ The blood pressure was taken with the participant seated using a calibrated baumanometer and stethoscope. The 9-centimetre cuff was used for respondents 


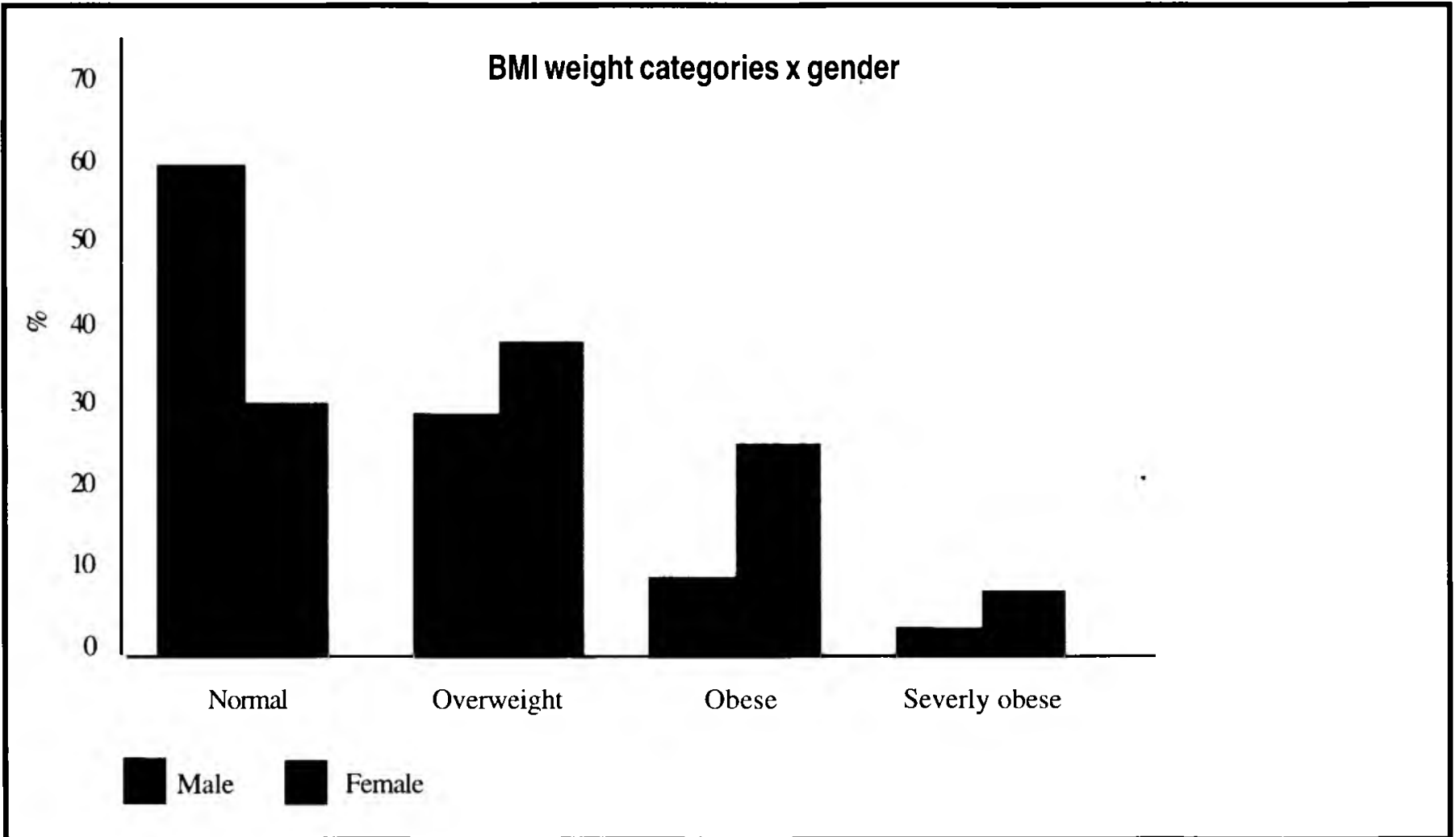

with a mid-upper arm circumference of 22-36 centimetres. The 12-centimetre cuff was used when the midupper arm circumference exceeded 36 centimetres. The normal values for blood pressure were considered as greater than $100 / 70 \mathrm{mmHg}$ and less than $140 / 90 \mathrm{mmHg}$.

- The weight and height measurements were done using a Detecto scale. The respondents' body mass index (BMI) was calculated using the standard formula of weight in $\mathrm{kg} /$ height in $\mathrm{m}^{2}$. The BMI categories used for the study are normal, overweight, obese, and severely obese.

- Measuring of the hip and waist circumference was done directly after the participant's height was measured. In male respondents in the upright position, the circumference of the waist was measured with a fibreglass tape measure to the nearest 0.5 centimetre at the level of the umbilicus at the expiration, while the respondents were breathing normally. In female respondents, the waist circumference was measured in the same way but at the narrowest point between the rib cage and the iliac crest. The hip circumference was measured at the level of the greater trochanter. Both measurements were taken in the horizontal plane (Luepker et al., 2004).

The blood glucose was done using an Accucheck glucometer. Blood was obtained using a finger prick with a sterile lancet. The normal values for the blood glucose were taken as $3.5-6.2 \mathrm{mmol} / \mathrm{l}$ (Meyer et al., 2002:Appendix 2). The blood glucose result is a random blood glucose as the participants did have breakfast. The blood glucose was determined approximately four to five hours after breakfast.

Physical activity was assessed through three questions. The fieldworkers asked the community members the questions and explained the question if the person did not understand. These questions are not exhaustive and were used as an exploratory instrument in the community's physical activity profile:

- $\quad$ Question 1: Current physical activity levels. The participants had to indicate the most appropriate description of their current level of physical fitness. The five categories were: poor, fair, acceptable, good and excellent. The data were used to derive two categories of physical activity: Poor (poor and fair) and acceptable (acceptable, good and excellent).

- Question 2: Work and/or daily activity. This question explored the amount of exercise obtained from daily work and activity. Four categories are available, namely: sitting down mostly and not walking much; walking about but not carrying heavy loads; walking and carrying heavy loads; and heavy manual labour.

- Question 3: Physical activity status. Physical exercise was assessed by establishing the frequency of physical exercise the past three months. Three categories of exercise were derived from this data: inactive; somewhat to reasonably active; and very active.

The validity and reliability of the measurements was ensured as the physical measurements were done by registered professional nurses and nursing students who are competent in 


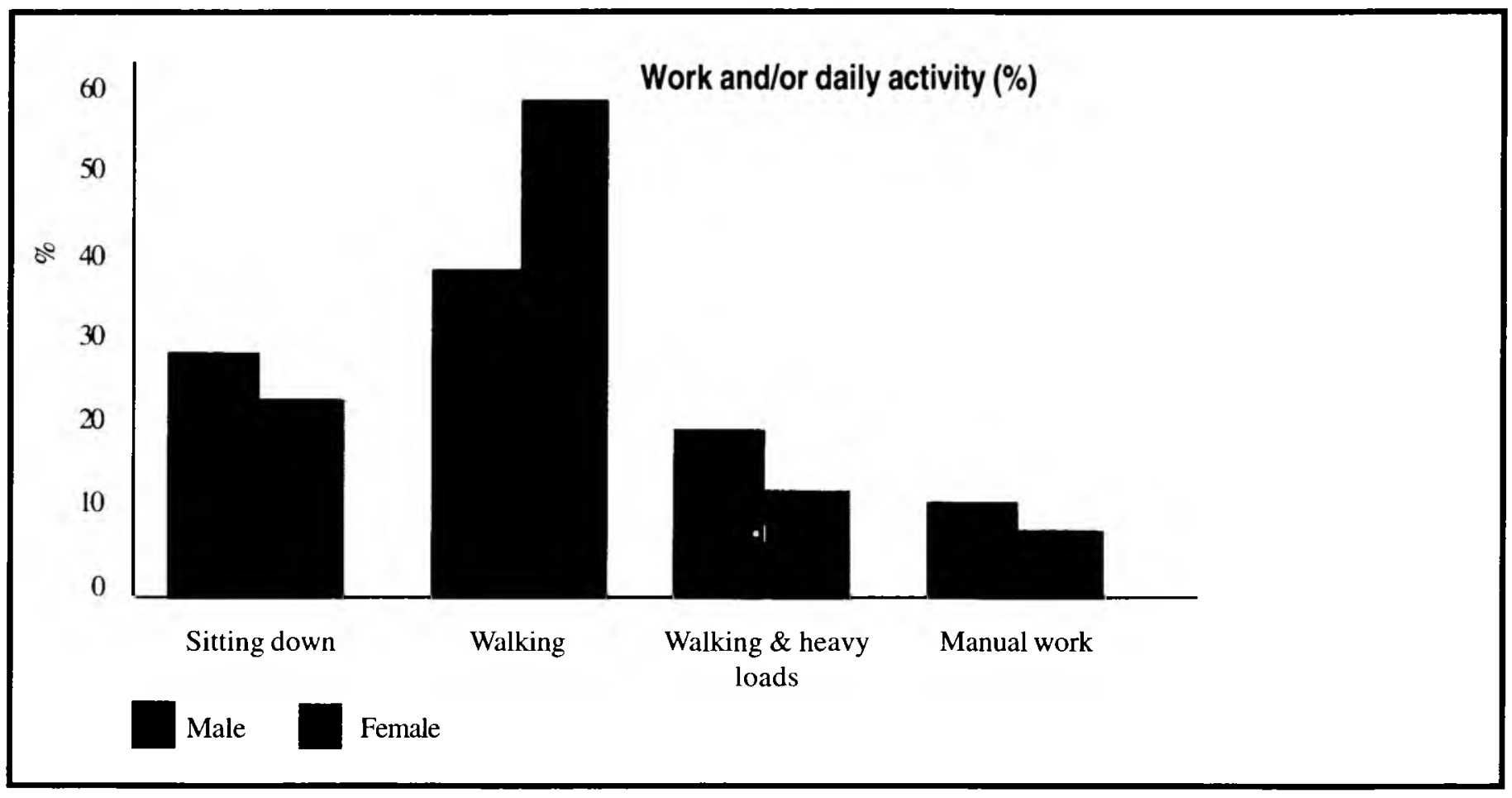

performing these procedures. The equipment was calibrated and one person did the same measurement throughout.

\section{Ethical considerations}

The following ethical principles were complied with (Polit \& Hungler, 1997:134):

- Informed consent. The participants had adequate information and an explanation in their language if required. They participated voluntarily in the study and could terminate their participation at any time.

- Nonmaleficence. Participants were not harmed in any way and were not forced to disclose any information if they did not wish to do so. They were informed about the finger prick to determine the blood glucose.

- Beneficence. Sensitivity to the participants was observed throughout the data collection process, and the study will lead to community-based interventions to reduce the prevalence of risk factors for chronic non-communicable disease in later life.

- Anonymity and confidentiality. Anonymity and confidentiality was maintained. While the registration form did contain the names and registration numbers of the participants, when the data were coded only the sequential number was used. As the lifestyle risks are real risks in the lives of these people, each participant that was identified with a risk in terms of international criteria received a letter of referral to a primary care clinic or general practitioner.

\section{Results of the study}

The results of the study will be presented in terms of the lifestyle risks identified for the group $(n=218)$.

\section{Hypertension}

The prevalence of hypertension was $45.8 \%$ for the men and $46.1 \%$ for the women. Figure 2 presents the participants who were hypertensive cross tabulated with the age groups. The men and women presented a different pattern. Of the men who were hypertensive, $64.7 \%$ were between 20 and 39 years of age. The women had a gradual increase in the number of hypertensive women with the highest percentage $(26 \%)$ in the 40-49 year age group.

\section{Obesity}

The weight categories according to the BMI index, cross tabulated with gender, are presented in Figure 3. Of the men, $40.9 \%$ are in the overweight, obese or severely obese categories whilst $69.8 \%$ of the females fell in these categories. These figures are much higher than the national average reported for South Africa in 2004. Reddy (2004:182) indicated the national prevalence for obesity as $29 \%$ for men and $56 \%$ for women. The male and female groups differed in terms of the degree of obesity. More men were overweight $(70 \%)$ than women $(52.5 \%)$, whereas the figure for the obese category was $20 \%$ (men) and $36 \%$ (women). The severely obese category was almost identical with $10 \%$ and $11 \%$ for men and women respectively.

\section{Waist-hip ratio}

A waist-hip ratio above the cut off point (men $>1.00$ and women $>0.85$ ) indicates a higher risk for cardiovascular disease. Only $20 \%$ of the men exceeded the ratio but almost half of the women $(49.7 \%$ ) demonstrated a higher risk. Again for the women, the highest percentage is in the $40-49$ and 50-59 year age groups (52.4\%).

\section{High blood glucose level}

The blood glucose level was a random blood glucose test. It must be stated that the measurements were done from 12:00 to $14: 00$ after the church service. High blood glucose values were demonstrated for $21.6 \%$ of the combined group, of which $83 \%$ were women. Again, the highest risk was in the age groups between 30-59 years of age. The range of the high blood glucose levels was from $6.4-23 \mathrm{mmol} /$. 
FIGURE 5: Participant's physical activity status ( $n=218)$

\section{Physical activity status (\%)}

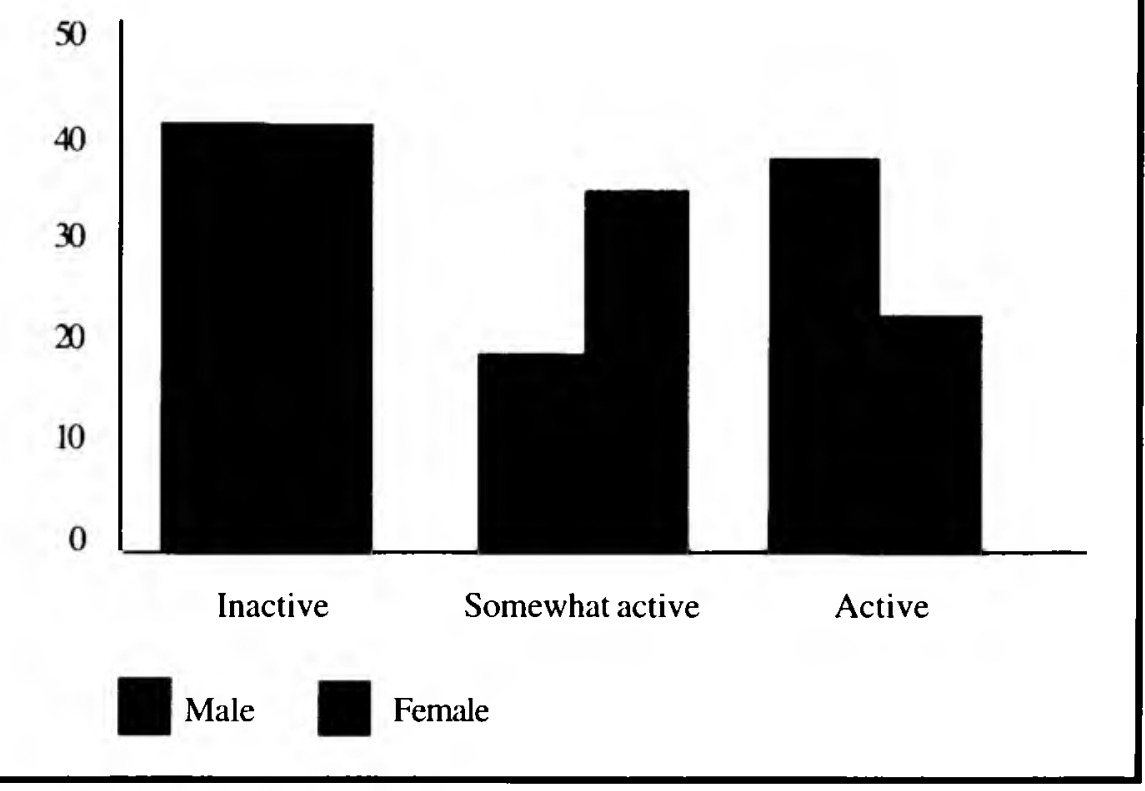

\section{Physical activity}

The results of the three questions were as follows:

\section{Question1:}

The men's perceptions of their current physical activity levels were better than those of the women. Of the men, $27 \%$ regarded their activity levels as poor compared to $39 \%$ of the women. In addition, $48 \%$ of the men thought their activity levels were good as compared to $36 \%$ of women. If the acceptable, good and excellent categories were combined, the results indicated that $73 \%$ of the men and $61 \%$ of the women considered their physical activity level as acceptable or better.

\section{Question 2:}

The results of the second question are presented in Figure 4. When asked about their work and/or daily activity, a different perspective was evident. In Figure 4, 29\% of men and $22 \%$ of the women indicated that during their work and daily living, they sit down and do not walk about much (category 1). The majority of the community members ( $43 \%$ for men and $57 \%$ for women) indicated that their daily activity fell into the second category, namely, walking about a lot, but not carrying heavy loads. Only $28 \%$ of men and $21 \%$ of women indicated manual labour and carrying heavy loads as part of their work or daily activities.

\section{Question 3:}

The focus of the third question is to determine the physical activity status of the person over the last three months. The results were grouped in three categories namely inactive, somewhat to reasonably active and very active. As is shown in Figure 5, 43\% of both men and women were in the inactive category with only $38.6 \%$ of men and $22.2 \%$ of women in the active to very active category.

\section{Discussion}

The purpose of this article is to report the results of several lifestyle risks in a community and to deliberate how best to proceed with the interventions - so often a survey is done, but what then? Once the risk factors are known, how should a group proceed with the development of an intervention? Several health risks were identified in the study.

- $\quad$ The pattern of hypertension displayed by the men is of particular concern. The high prevalence of hypertension in the 20-39 year old men requires urgent attention. From the data, it is evident that in this sample, the younger men weigh more and are more hypertensive than expected.

- $\quad$ Of specific concern is the high prevalence of obesity (almost $41 \%$ for men and $71 \%$ for the women). As reported earlier, two thirds of persons whose weight is in the above normal BMI categories do not perceive themselves to be overweight (Reddy, 2004:182). With slenderness often being equated to a HIV positive status, and the cultural penchant for a fuller figure, this battle of the bulge is far from over. No quick-fix intervention will suffice.

\section{Almost half the women} displayed a high waist-hip ratio. Haslam (2005:455) highlights the negative effects of abdominal obesity. The accumulation of adipose tissue within the omentum, abdomen, and around abdominal organs is a key factor in the development and progression of cardiovascular disease.

The data regarding the physical activity reveals a discrepancy between the community members' evaluation of their current physical activity levels and what they are actually doing. The majority of both men $(73 \%)$ and women $(61 \%)$ indicated that their current physical activity level was good or at least acceptable. However, the two questions elating to their work and daily living and their exercise activity over the past three months point towards just the opposite. More than two thirds of the group for both questions indicated a lack of exercise either at work and/or daily living or in an exerciserelated activity. As with obesity, the community member's selfevaluation of their activity level and what they actually do does not correspond. Their evaluations may be positive, but are not substantiated by reality.

The disturbing aspect of the group with high blood glucose is that of the 47 persons with high blood glucose, only 5 were diagnosed with diabetes mellitus and actively on treatment. The majority (almost $90 \%$ ), were undiagnosed and untreated. Of these 47 individuals, 15 had high blood 
pressure and 32 were either overweight, obese or severely obese.

The potential for cardiovascular and metabolic health problems in future are clearly evident in this group. An intervention, based on the results of the study, should and must be developed and implemented. The more challenging question is to know what to do and how to do it.

\section{The way forward}

Health promotion is the process of enabling people to increase control over and improve their health. In the short history of health promotion, many historic events occurred to guide the health promotion practitioner forward. Most notably and well known are the Ottawa Charter (World Health Organisation (1986:5-6), the Jakarta Declaration on Health Promotion (Norten, 1998:1270) and now the Bangkok Charter on Health Promotion (World Health Organisation, 2005). In South Africa, health promotion is guided by four major approaches which are (Coulson, 1999:8ff):

-
- $\quad$ environments;
- $\quad$ education and information; and
re-orienting health services and
community participation.

Health promotion is considered a community service and should provide outreach work into health districts. Though the above provide a macro framework within which to structure a health promotion intervention, the specific components of such an intervention are less clear and mostly unknown

Green and Kreuter (1991:no page number) proposed a conceptual model for planning and evaluating behaviour change interventions targeting chronic diseases. The authors propose that the risk factors, the behaviours, and determinants of the risk factors must be known and included in the intervention. A variety of health promotion strategies that will address the problem on various levels have to be developed and tested. The importance of these components must not be underestimated. So much more needs to be known before an intervention can be planned. Research needs to be done on the risk behaviours and risk factors.

some ideas.

Without a clear understanding of the interrelationships of the determinants of the risk factors, a successful intervention is not possible (Reddy, 2004:186). Knowledge about the determinants is a prerequisite to targeting the points that will bring about a change in the risk behaviours or factors. In a multi-cultural country such as South Africa, the importance of research in this area is pivotal and probably underestimated. The focus is currently not on noncommunicable diseases but on the socalled deadly trio: HIV and AIDS, tuberculosis and malaria.

The Department of Nursing Science, once the data analysis of the survey was completed and the extent of the risk factors in the community was realised, had a 'what now?' experience. For example, in planning to develop an intervention to change the community's eating habits to reduce the prevalence of obesity, several questions need to be asked: What do they eat? How much money do they have to buy food? How do they prepare their food? What barriers could be obstacles in changing these habits? What would be considered as acceptable food? Who should be taught about eating habits? How should they be taught? Will they be willing to change? Who should educate them? How should they be educated? Could the fact that the participants were active members of a church have a positive effect on their participation in the intervention?

So much more needs to be known. An expectation was raised in the community due to the survey that was done and an intervention is clearly needed. What is the way forward?

As a result of the deliberations in the department, a framework (figure 6) was developed to guide the development of an intervention. Due to the complexity of all that should be taken into account when developing an intervention, the framework will enable the research team to evaluate what is known and what research should be done to guide the intervention. The intention is not to suggest that all that could be taken into account is contained in the framework; indeed every person with some health promotion background who reads the article will most probably be able to add
Health promotion is an integral part of any health problem solution. Recently however, several articles discussing health promotion in a global context described health promotion as weak; though many declarations and guidelines exist, these are often not implemented. The health promotion approach suggests a comprehensive and intersectoral approach and should focus on people from before birth to old age. If health promotion does not become 'strong', substantial effort and finance will be spent to no avail. As Shinawatra emphasised at the $6^{\text {th }}$ Global Conference on Health Promotion (WHO, 2005), the focus should be on building rather than repairing health. Good health is key to progress and thus building health has become a priority in national and global agendas.

\section{Acknowledgements}

The personnel and second year nursing students of the Department of Nursing Science, Tshwane University of Technology 2004

\section{References}

BOURNE, LT; LAMBERT, EV \& STEYN, K 2002: Where does the black population in South Africa stand on the nutrition transtition? Public Health Nutrition, Feb:5(1A):157-62.

BURNS, N \& GROVE, SK 1997: The practice of nursing research conduct: critique \& utilization. Philadelphia: WB Saunders.

COULSON, N 1999: Health promotion. In: Health Systems Trust. South African Health Review. Durban: The Gang Press.

GREEN, LW \& KREUTER, MW 1991: Health promotion planning: an educational and environmental approach. $2^{\text {nd }}$ ed. Mountain View, CA: Mayfield.

HASLAM, D 2005: Include measurement of waist circumference in GP contract. British Medical Journal, 331:455-456.

INTERNATIONAL COUNCIL OF NURSES 2003: Fact sheet - ICN on obesity. [Online]. Available at: $<$ http:// www.icn.ch/matters obesity.htm $>$. 
Survey results with several life style risk factors identified

Knowledge to be available for development and implementation of a health promotion intervention

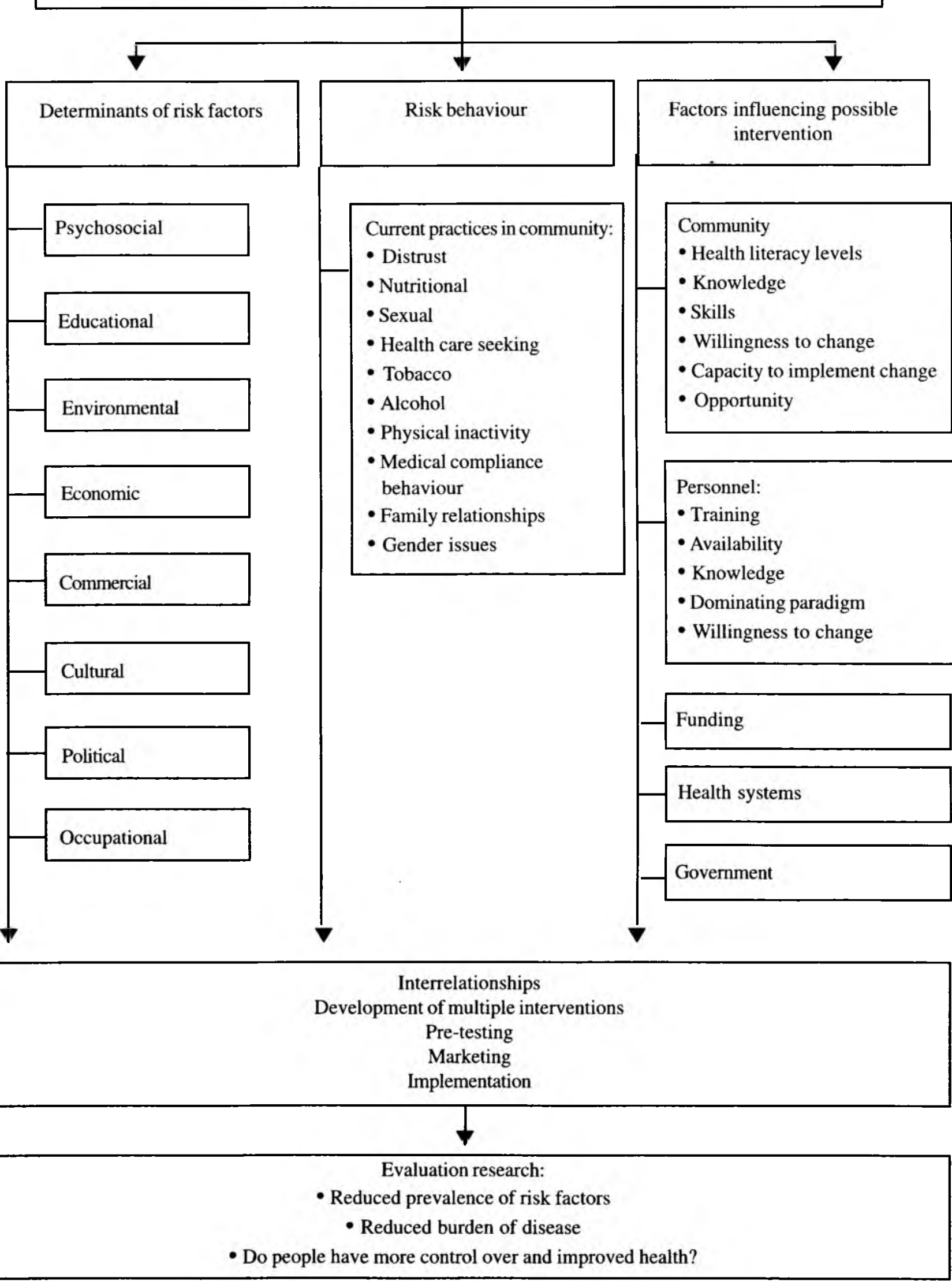


KRUGER, HS; VENTER, CS \& VORSTER, HH 2003: Physical inactivity as risk factor for cardiovascular disease in communities undergoing rural to urban transition: the THUSA study. Cardiovascular Journal of South Africa, Jan-Feb.14(1): 16-23.

LUEPKER, RV; EVANS,A; MCKEIGUE, P\& REDDY, KS 2004: Cardiovascular survey methods. $3^{\text {rd }}$ ed. Geneva: World Health Organization.

MEYER, BJ; VAN PAPENDORP, DH; MEIJ,HS \& VILJOEN, M 2002: Human physiology. $3^{\text {rd }}$ ed. Lansdowne: Juta.

NORTEN, L 1998: Health promotion and health education: what role should the nurse adopt in practice. Journal of Advanced Nursing, 28: 1269-1275.

PELTZER, K 2001: Knowledge and attitudes of primary care nurses and midwifes towards health promotion in rural South Africa. Curationis, 24(4): 5258.

POLIT, DF \& HUNGLER, BP 1997: Essentials of nursing research: methods, appraisal, and utilization. $4^{\text {th }}$ ed. Philadelphia: Lippincott.

REDDY, P 2004: Chronic diseases. In: Health Systems Trust. South African Health Review. Durban: The Gang Press.

STEYN,K; KAZENELLENBOGEN,JM; LOMBARD, CJ \& BOURNE, LT 1997: Urbanization and the risk for chronic diseases of lifestyle in the black population of the Cape Peninsula, South Africa. Journal of Cardiovascular Risk, April:4(2):135-42.

VAN ROOYEN, JM; HUISMAN, HW; ELOFF, FC; LAUBSHER, PJ; MALAN, L; STEYN, HS \& MALAN, NT 2002: Cardiovascular reactivity in Black South African males of different age groups: the influence of urbanisation. Ethnicity Discourse, Winter:12(1):69-75.

WORLD HEALTH ORGANISATION 1986: Ottawa Charter for Health Promotion, Copenhagen: WHO

WORLD HEALTH ORGANISATION 2005: Bangkok Charter for Health Promotion. Available at: http:// www.who.int/mediacentre. Accessed: 